OPEN ACCESS

Edited by:

Mari Niva,

University of Helsinki, Finland

Reviewed by:

Atle Wehn Hegnes,

Norwegian Institute of Bioeconomy

Research, Norway

Steven McGreevy,

Research Institute for Humanity and

Nature, Japan

*Correspondence:

Magnus Boström

magnus.bostrom@oru.se

Specialty section: This article was submitted to

Sustainable Consumption,

a section of the journal

Frontiers in Sustainability

Received: 16 June 2021

Accepted: 19 August 2021

Published: 10 September 2021

Citation:

Boström M (2021) Take the

Opportunity Afforded by the COVID-19 Experiences: Progressive Non-growth Policies for Sustainable Lifestyles. Front. Sustain. 2:726320.

doi: 10.3389/frsus.2021.726320

\section{Take the Opportunity Afforded by the COVID-19 Experiences: Progressive Non-growth Policies for Sustainable Lifestyles}

\author{
Magnus Boström* \\ School of Humanities, Education, and Social Sciences, Örebro University, Örebro, Sweden
}

The COVID-19 pandemic has led to significant restrictions on lifestyles and consumption everywhere. Many consumer practices have been disrupted due to the shutting down of economic and social activities, limiting of mobility in public places, closing of shopping centers and non-essential stores, and closing of borders. These restrictions have had a significant impact on climate emissions. Much public and scholarly attention has been given to the question of whether the pandemic also offers a window of opportunity for long-term sustainability transformation. The article elaborates on this issue by specifically discussing progressive non-growth policies for sustainable lifestyles and reduced consumption. What potential for long-term transformative change results from lifestyle changes like these? How can societies be restructured to take advantage of the experiences from the pandemic? Bottom-up drivers and possibilities for top-down enforcement are both important to consider. The article limits its focus to top-down policy measures with transformative potential related to sustainable lifestyles (reduced consumption) by summarizing and discussing some key policy lessons identified in recent COVID-19 literature. It considers the need to address likely rebound effects and the vested interests in bouncing practices back toward the previous unsustainable "normality." The argument is generally inspired by post-growth and degrowth perspectives, as the dominant pro-growth, neo-liberal doctrines are seen as unable to transform societies and guide them onto sustainable paths.

Keywords: climate change, consumption, degrowth, transformation, transformative change, infrastructure, postgrowth, sustainability

\section{INTRODUCTION}

Everywhere around the world, the COVID-19 pandemic has led to significant restrictions on lifestyles and consumption. Many consumer practices have been disrupted due to the shutting down of economic and social activities, limiting of mobility in public places, closing of shopping centers and non-essential stores, and closing of borders. Given these unexpected circumstances, great public and scholarly attention has been given to the question of whether the pandemic also offers a window of opportunity for-and possibilities to enforce-sustainability transformation (e.g., Cohen, 2020; Lidskog et al., 2020; Perkins et al., 2021). This article specifically focuses on top-down policies for sustainable lifestyles and reduced consumption. 
The pandemic has certainly resulted in immediate lifestyle changes with clear impact on climate emissions. In any country of investigation, there has been an overall decline in consumption (Jo et al., 2021). For instance, oil and energy consumption have dropped (Bahmanyar et al., 2020; Iqbal et al., 2020; Aktar et al., 2021; Perkins et al., 2021), with an accelerated switch to renewables (Kanda and Kivimaa, 2020; Jiang et al., 2021). There is an overall decline in transport modes such as aviation (Gössling, 2020) and public transportation (De Haas et al., 2020; Eisenmann et al., 2021), a sharp decline in consumption related to tourism, and in consumption of commoditized leisure services (restaurants, accommodation, museums, amusement parks) related to the hospitality industry (Ehgartner and Boons, 2020; Jones and Comfort, 2020; Jo et al., 2021). There have been significantly fewer trips to supermarkets (Esposti et al., 2021) and a sharp decrease in consumption of clothing and shoes, although this trend is counteracted by increased online shopping (Jiang et al., 2021). The reduction of consumption further relates to a decline of income stemming from a significant drop in global working hours (Perkins et al., 2021). Financial stress and economic uncertainty can give rise to more conscious use of resources and frugality (Borsellino et al., 2020; Zwanka and Buff, 2020; Echegaray, 2021; Mont et al., 2021; Tchetchik et al., 2021). There are also examples of increased consumption and use, for instance regarding disposable plastics (da Costa, 2021).

What potential for long-term transformative change is gained from lifestyle changes like these? How can societies be restructured to take advantage of the experiences from the pandemic? Such questions must be explored from many angles, giving attention to both bottom-up drivers and top-down enforcement, as well as to their interaction. Many changes evolve from bottom-up processes led by the public and by for-profit and non-profit organizations through the development of new preferences, ideas, values, practices, social norms, technologies, and transformative learning (Boström et al., 2018). Such bottomup creativity and pressure are essential and can demonstrate promising paths as well as indicate public legitimacy for progressive top-down politics and policy. However, top-down policy measures are needed to achieve structural change on a sufficient scale, uptake and permanence, as well as to counteract unsustainable structures and forces. The argument put forward here is that politicians and policymakers can and should take advantage of new pandemic-related experiences in everyday life, which may not only be of a negative kind. The focus of this article is limited to reflecting on top-down policy measures with transformative potential related to sustainable lifestyles (reduced consumption) by summarizing and discussing some key policy lessons identified in recent COVID-19 literature.

It is critical to bear in mind that politics, policy and planning will need to address the likely rebound effects and the vested interests in bouncing practices back toward the previous "normality," a normality which was profoundly unsustainable. Therefore, the article is generally inspired by non-growth theoretical perspectives, including those of postgrowth (Jackson, 2017), degrowth (Kallis et al., 2018; Diesendorf, 2020), sufficiency (Princen, 2005), and economies of plenitude (Schor and Thompson, 2014), as I see the currently dominant pro-growth, neo-liberal doctrine as fundamentally unable to transform societies and lead them onto sustainable paths.

The review takes the form of an integrative literature review (Snyder, 2019), which is more selective than a systematic literature review, and aims to synthesize literature on a research topic to allow new perspectives to emerge. I conducted a literature search and delimited the selection in two steps, first, COVID-19 literature on (un)sustainable consumption, lifestyle and everyday practices, and second, a subset of this sample which discussed policy-related implications. I also included some earlier studies to broaden the perspective.

\section{INCORPORATING THE (EXTREMELY LIKELY) RISK OF BACKLASH INTO POLICY}

"The fear is that most of the changes seen in 2020 are expected to be transient because they do not reflect systematic long-term changes in the energy systems, transportation, or economics" (Aktar et al., 2021, p. 76). Aktar et al. (2021) address the risk of a rebound effect, arguing that it is extraordinarily difficult to address the triple problem of COVID-19, economic destruction and climate change. The rebound effect refers to the net effect when resource use increases despite improved resource efficiencies, which happens because growth in demand outstrips the effect of efficiency gain. Decreased demand for some products may also free up resources for increased demand for other products where resource consumption is less visible. Freire-Gonzalez and Vivanco, 2020 (see also Chen et al., 2020) discuss this possible risk in relation to ICT. The use of ICT has been accelerating in many areas, including teleworking, online shopping, remote social relationships, surveillance technology, and various forms of entertainment, particularly during the pandemic. Digitalization is generally thought of as environmentally beneficial, because it is expected to reduce transport, but the above authors' review of previous studies suggests a need to modify this hope. People may seize the opportunities afforded by digitalization while nonetheless keeping their car for other purposes than commuting (e.g., vacationing). Alongside ICT, there might also be a material, water and energy rebound due to the need for more space because of more home-based work (Jiang et al., 2021). Hence, digitalization and home-based work will not be a panacea, and to prevent rebound from happening additional policy measures will be needed that set limits on consumption and resource use (Princen, 2005; Fuchs et al., 2021).

Moreover, there is the problem of pent-up demand (Sheth, 2020). Many consumer desires from pre-COVID-19, which have been difficult to satisfy during the pandemic, will remain and their fulfillment will be postponed. People may shift their demands, such as for a long-distance vacation, from now into the future, and feel justified in doing so (Cocolas et al., 2020). Additionally, even if people change preferences and perhaps even accept new values such as downsizing, the existing institutions and infrastructural factors may force people back into previous mass consumption habits. For example, existing transport infrastructures cannot just be wished away. Even if 
people want to use their cars less, because of more home-based work, they may be still reliant on them.

At the same time, new experiences should not be disregarded. Adopting a social-practice perspective, Ehgartner and Boons (2020) discuss factors that could prevent activities from bouncing back. These include people having had sufficient time to learn new practices, lacking the resources to continue old practices, being able to utilize new infrastructures and facilities that support new practices, being prohibited by new regulations that eliminate some of their previous practices, and being assisted by a new cultural context (e.g., social norms). Even if policies ought to address the risk of backlash, they can build on opportunities gained from the changed practices, including the competencies, learning, and even quality of life experiences that people have gained.

Finally, and probably most importantly, there are vested interests contained in capitalist, industrialist structures, in the economic geographies of mass production, distribution and consumption, and in pro-growth dogmas, welfare policies and consumer culture (Boström, 2020). Because of these structures, there are and will be massive promotional efforts, from both business and politics, to return us to the "normality" of high-consumption, energy-intensive lifestyles (Cohen, 2020, Diesendorf, 2020). How can all this be counteracted?

\section{NON-GROWTH POLICIES FOR DOWNSIZED LIFESTYLES}

\section{Public Legitimacy for Hard, Top-Down Intervention}

A first but crucial point to consider is public legitimacy for hard, top-down intervention. The pandemic itself has demonstrated broad public acceptance of hard intervention and a strong role of the state. This is because the risk is considered immediate and serious, and everyone is thought to have the duty to comply with proper protective protocols. The question is whether (a sufficient portion of) the public has also become more accepting of interventions in other areas such as climate change. The problem is that climate change may continue to appear as a less immediate and more abstract threat (Lidskog et al., 2020), and people may be tired of being subjected to restrictions and desire a rapid return to "normality." Nonetheless, the public perceives the need for significant and enduring top-down restrictions during the current public health crisis, and may accordingly have developed a greater propensity for accepting similar measures in the near future (De Haas et al., 2020), not least due to increasingly sharp messages from the IPCC about climate warming (2021). The key policy lesson is to take advantage of this collective experience. People could adapt (Kirk and Rifkin, 2020). People could take responsibility (Perkins et al., 2021).

\section{Integrate Health and Environment}

The public has become sensitized to how health, environment, and equality are interrelated. The intersection of these areas could be more explicitly and forcefully utilized in public policy (Stegeman et al., 2020), with both relatively soft approaches such as food diet recommendations (Détang-Dessendre et al., 2020) and more infrastructural issues such as promoting active transportation and clean air in urban areas (Severo et al., 2021).

\section{Facilitate Further Digitalization and Home-Based Work}

Accelerated digitalization and the transition to home-based work offer a crucial opportunity to decrease car dependency. An obvious path for policy is to support the further establishment of digitalization infrastructure and also to counteract patterns and risks of digital divides (Bin et al., 2021; Jiang et al., 2021; Jo et al., 2021). Such infrastructures will facilitate self-governance among organizations to support home-based work and reduce office space and need for travel. However, because of the likely rebound effects discussed above, further top-down measures will be necessary (see following items).

\section{Support Sharing, Repairing, and Alternative Economies}

COVID-19 has, at least in some places, contributed to an increase in biking and bike-sharing (Bergantino et al., 2021; Mont et al., 2021). Also, the number of platforms for carsharing has increased (Eisenmann et al., 2021), while services related to accommodation (Airbnb) and transportation (Uber) have reported losses (Hossain, 2021, Mont et al., 2021). Studies stress the importance of facilitating community structures for promoting degrowth practices such as bike-sharing or repairing, also post-COVID (Bergantino et al., 2021). Some structures of this sort may also be supportive of the local economy (Ehgartner and Boons, 2020). Public policy could also further provide recognition, protective space, and material support to various civil society initiatives or alternative non-growth movements, including the transition town networks, alternative agrifood movements, eco-communities, cooperatives, time-banking networks, and convivialist movements, all of which construct innovative, alternative, non-growth economies including novel ways to foster social sustainability (Schor and Thompson, 2014; Kallis et al., 2018).

\section{Decrease Car Dependency}

Because of rebound effects and existing traffic infrastructure, digitalization alone will not decrease car dependency. In particular, this is because the public has been forced or driven toward individual modes of transportation during the pandemic, which necessitates policies counteracting the expected increase in car dependency (Zhang et al., 2021). These should be coupled with promotional measures to support active transportation, such as bicycling (Bergantino et al., 2021). An interesting concept that may stimulate creativity and innovation in local policy and planning is the " 15 min city"; that is, cities/areas where one can access most essential everyday services within 15 mins by foot or bike. Such a city would support a lifestyle less dependent on cars, and offer more road space for walking and cycling (Jiang et al., 2021). Nature-based solutions for parks (blue and green infrastructure), buildings (green roofs, green walls) and green streets (trees) would be prioritized. Centralized supplies would be replaced by more distributed ones. Green spaces offer people the 
possibility to thrive and socialize together with joint walks and activities without resorting to practices of excessive consumerism and commoditized experience. New infrastructural solutions would include more space for community gardens, new means of food provisioning and delivery (Ben Hassen et al., 2020), and possibilities for shorter food supply chains (Butu et al., 2020).

\section{Restore Trust in Public Transportation}

Apart from the many opportunities that the pandemic experience offers, there is also a risk of it permanently damaging previous environmentally benign practices and structures such as traveling by public transportation. Restoring trust in public transportation, such as commuter trains, is key. This might require both pull factors (creating safe individual spaces, adopting protective measures in the vehicles) and push factors $\left(\mathrm{CO}_{2}\right.$ taxes, subsidies) to compensate for lost trust in public transportation (Eisenmann et al., 2021).

\section{Restrict Domestic and International Travel by Air}

Further restrictions on domestic and international travel ought to be tested (Hall et al., 2020), such as rationing and drastically higher and progressive taxes/prices for aviation. COVID19 offers a unique opportunity to critically rethink aviation governance, because the aviation industry faces more problems than just climate impact, including small and even negative profit margins and heavy reliance on state aid (Gössling, 2020; Gössling and Humpe, 2020; Shamshiripour et al., 2020). Demand is induced by very low fares. The opportunity to explore an alternative business model could also be extended to a critical rethinking of the (un)sustainability of the hospitality industry (Jones and Comfort, 2020). There are many new promising ideas and values around "slow," local, and small-scale tourism that parts of the tourism and transportation (e.g. railways) sector could connect with and public policy could support (Ateljevic, 2020; Benjamin et al., 2020; Hall et al., 2020; Wen et al., 2020).

Admittedly, current policy focuses almost exclusively on the economic recovery of the existing aviation industry rather than its reduction and transformation (Hall et al., 2020). Likewise, Jones and Comfort (2020) argue that there are not enough stakeholders in the tourism and hospitality industry "that question the sustainability of success defined by growth in visitor numbers or increases in material consumption to expect transformational change driven from within." (p. 591) This harsh reality does not make it less true that a fundamental transformation within the sector is necessary in the long run.

\section{Accelerate the Transition to Renewable Energy}

Even from a degrowth perspective, some sectors will have to grow. There are great possibilities for shifting toward renewable energy, which has already happened during the pandemic. However, further public policy support is needed (Iqbal et al., 2020), such as subsidies for solar panel investment and largescale divestment in fossil fuel energy. The public sector could use hard intervention to regulate the banking systems, as well to ensure full scale divestment of the fossil economy in the public pension system.

\section{Facilitate a Transition to Low Carbon Jobs With Progressive Fiscal Policy}

Modern Monetary Theory-which has been applied during the pandemic (Diesendorf, 2020), though sometimes with very dubious goals such as saving the aviation industry-could be utilized for a return to more low-carbon jobs. Diesendorf makes the argument that this utilization of MMT during the pandemic provides an opening for governments to set aside neoliberal economic ideologies and austerity policies. Before the pandemic, Jackson (2017) argued that the post-growth society will be a society based on services such as care, craft and culture, rather than one reliant on material possessions. Other job-related measures that can have an impact on worklife balance, contribute to a reduction of consumption and promote more sustainable lifestyles are facilitating home-based work and workweek reduction. Particularly the latter is a core degrowth policy, which in addition to reducing production and consumption (by lowering income) can reduce stress and time-poverty, free up time for cultivating alternative practices (repairing, gardening, etc.) and enhance quality of life (Schor and Thompson, 2014; Kallis et al., 2018). Measures like these require progressive taxes and a return to progressive fiscal policy.

\section{Combat Social Inequality}

Highly unequal abilities to cope with COVID-19 have been revealed among the population (De Groot and Lemanski, 2020). Social stratification, including the digital divide, is a critical issue for many reasons. One is to ensure legitimacy for hard interventions targeting overconsumption. Inclusion and equality are essential to consider in policy, otherwise there will be yellow vests and gasoline rebellions. According to Stegeman et al. (2020) there is a need for policies that simultaneously address environment, health and equity related to such topics as urban spaces, mobility and consumption. Ashford et al. (2020) argue that policy intervention is needed to achieve economic recovery and social (in)equalities that do not reproduce unsustainable pre-pandemic patterns. They identify 30 policy interventions focused on addressing inequality, some of which concern sustainable consumption. These include policy interventions such as universal basic income schemes, reducing the working week, shifting focus from products to product services (e.g., from car ownership to mobility services), discouraging excessive consumption with taxes such as luxury taxes, educating workers/consumers for a slowergrowing economy, and regulating advertisement (Ashford et al., 2020). Thus, changing patterns of demand and intentionally slowing down growth must go hand in hand with measures to combat inequality.

\section{DISCUSSION}

To many, measures like those described in the previous section may sound naive and impossible to realize. To me, the belief that we can avoid measures like these and still reach the $1.5 \mathrm{C}$ 
Paris agreement sounds naive and impossible. The list of policy measures is not exhaustive, and such ideas existed before the pandemic. However, the disruption of many consumer practices is what may have made them more imaginable, and there is potential for broader public acceptance of harder interventions. The chances for a more radical growth-critical perspective to take root in societies, also on the political level, are only likely to be realized if dominant public discourses accept that we are living in a time of crisis. Indeed, the structural weakness of the growth imperative is revealed by the COVID-19 crisis (Spash, 2020). Protecting the economy has been the core priority. The environment will have to wait. The pandemic exposed the structure of the global supply chains and their fragility.

The hope, says Spash (2020), is "that the experience of a devastating global crisis will put the necessity of systems change high on the public agenda and create general awareness that "the economy" cannot be allowed to go on as before, creating social division and gross inequalities while leaving humanity at the mercy of corporations, billionaires, speculators and "profiteers"” (p. 14).

In the long run, completely new ways to organize societies and economies will have to emerge. It is hard to see how progrowth capitalist/industrialist structures can be sustained. In the short and medium term it might however be necessary to utilize existing capitalist structures to facilitate a rapid transition to new technologies and innovations, such as those within renewable energy, while also rapidly counteracting the fossil fuel industry and downsizing the aviation and other highclimate-impact sectors. Meanwhile, alternative economic models and non-growth communities and practices must be developed,

\section{REFERENCES}

Aktar, M. A., Alam, M. M., and Al-Amin, A. Q. (2021). Global economic crisis, energy use, $\mathrm{CO}_{2}$ emissions, and policy roadmap amid COVID-19. Sustain. Prod. Consum. 26, 770-781. doi: 10.1016/j.spc.2020.12.029

Ashford, N. A., Hall, R. P., Arango-Quiroga, J., Metaxas, K. A., and Showalter, A. L. (2020). Addressing inequality: the first step beyond COVID-19 and towards sustainability. Sustainability 12:5404. doi: 10.3390/su12135404

Ateljevic, I. (2020). Transforming the (tourism) world for good and (re)generating the potential 'new normal'. Tourism Geogr. 22, 467-475. doi: 10.1080/14616688.2020.1759134

Bahmanyar, A., Estebsari, A., and Ernst, D. (2020). The impact of different COVID-19 containment measures on electricity consumption in Europe. Energy Res. Soc. Sci. 68, doi: 10.1016/j.erss.2020.101683

Ben Hassen, T., El Bilali, H., and Allahyari, M. S. (2020). Impact of COVID19 on food behavior and consumption in Qatar. Sustainability 12:6973. doi: $10.3390 /$ su12176973

Benjamin, S., Dilette, A., and Alderman, D. H. (2020). "We can't return to normal": committing to tourism equity in the post-pandemic age. Tour. Geogr. 22, 476-483. doi: 10.1080/14616688.2020.1759130

Bergantino, A. S., Intini, M., and Tangari, L. (2021). Influencing factors for potential bike-sharing users: an empirical analysis during the COVID-19 pandemic. Res. Transp. Econ. 86:101028. doi: 10.1016/j.retrec.2020.101028

Bin, E., Andruetto, C., Susilo, Y., and Pernestål, A. (2021). The trade-off behaviours between virtual and physical activities during the first wave of the COVID-19 pandemic period. Eur. Transp. Res. Rev. 13, 1-19. doi: 10.1186/s12544-021-00473-7 with public sector support, and scaled up. We can foresee backlashes, but nonetheless a collective memory will remain that reminds us of how altered lifestyles and practices were possible during the pandemic. New hard intervention and infrastructural measures-even if they are piecemeal and fragmentary, and not easily framed within the spirit of a degrowth paradigm-can form stepping-stones for further measures and structural change.

\section{DATA AVAILABILITY STATEMENT}

The original contributions presented in the study are included in the article/supplementary material, further inquiries can be directed to the corresponding author/s.

\section{AUTHOR CONTRIBUTIONS}

The author confirms being the sole contributor of this work and has approved it for publication.

\section{FUNDING}

This article was written within the research project Learning to consume less: can experiences during the COVID-19 pandemic trigger lifestyle transformation? funded by Formas (2020-02849).

\section{ACKNOWLEDGMENTS}

The author is grateful for insightful comments by two reviewers, which have helped sharpen the arguments.

Borsellino, V., Kaliji, S. A., and Schimmenti, E. (2020). COVID-19 drives consumer behaviour and agro-food markets towards healthier and more sustainable patterns. Sustainability 12:1293. doi: 10.3390/su12208366

Boström, M. (2020). The social life of mass and excess consumption. Environ. Sociol. 6, 268-278. doi: 10.1080/23251042.2020.1755001

Boström, M., Andersson, E., Berg, M., Gustafsson, K., Gustavsson, E., Hysing, E., et al. (2018). Conditions for transformative learning for sustainable development: a theoretical review and approach. Sustainability 10:4479. doi: 10.3390/su10124479

Butu, A., Brumă, I. S., Tanasă, L., Rodino, S., Dinu Vasiliu, C., Dobo?, S., et al. (2020). The impact of Covid-19 crisis upon the consumer buying behavior on fresh vegatables directly from local producers. Case study: the quaranteened area of Sucaeva county Romania. Int. J. Environ. Res. Public Health 17:5485. doi: 10.3390/ijerph17155485

Chen, C. F., Zarazua de Rubens, G., Xu, X., and Li, J. (2020). Coronavirus comes home? Energy use, home energy management, and the social-psychological factors of COVID-19. Energy Res. Soc. Sci. 68:101688. doi: 10.1016/j.erss.2020. 101688

Cocolas, N., Walters, G., Ruhanen, L., and Higham, J. (2020). Consumer attitudes towards flying amidst growing climate concern. J. Sustain. Tour. 29, 944-963. doi: 10.1080/09669582.2020.1849234

Cohen, M. J. (2020). Does the COVID-19 outbreak mark the onset of a sustainable consumption transition? Sustain. Sci. Pract. Policy 16, 1-3 doi: 10.1080/15487733.2020.1740472

da Costa, J. P. (2021). The 2019 global pandemic and plastic pollution prevention measures: playing catch-up. Sci. Total Environ. 774:145806. doi: $10.1016 /$ j.scitotenv.2021.145806 
De Groot, J., and Lemanski, C. (2020). COVID-19 responses: infrastructure inequality and privileged capacity to transform everyday life in South Africa. Environ. Urban. 33, 255-272. doi: 10.1177/0956247820970094

De Haas, M., Faber, R., and Hamersma, M. (2020). How COVID-19 and the Dutch "intelligent lockdown" change activities, work and travel behaviour: evidence from longitudinal data in the Netherlands. Transp. Res. Interdiscip. Perspect. 6:100150. doi: 10.1016/j.trip.2020.100150

Détang-Dessendre, C., Guyomard, H., Requillart, V., and Soler, L.-G. (2020). Changing agricultural systems and food diets to prevent and mitigate global health stocks. Sustainability. 12:6462. doi: 10.3390/su12166462

Diesendorf, M. (2020). COVID-19 and economic recovery in compliance with climate targets. Glob. Sustain. 3:e36. doi: 10.1017/sus.2020.32

Echegaray, F. (2021). What POST-COVID-19 lifestyles may look like? Identifying scenarios and their implications for sustainability. Sustain. Prod. Consump. 27, 567-574. doi: 10.1016/j.spc.2021.01.025

Ehgartner, U., and Boons, F. (2020). Covid-19 and Practice Change in the Everyday Life Domains of Hygiene, Eating, Mobility, Shopping, Leisure, and Work. Implications for Environmental and Social Sustainability. Manchester: Sustainable Consumption Institute.

Eisenmann, C., Nobis, C., Kolarova, V., Lenz, B., and Winkler, C. (2021). Transport mode use during the COVID-19 lockdown period in Germany: the car became more important, public transport lost ground. Transp. Policy 103, 60-67. doi: 10.1016/j.tranpol.2021.01.012

Esposti, P. D., Mortara, A., and Roberti, G. (2021). Sharing and sustainable consumption in the era of covid-19. Sustainability 13:1903. doi: $10.3390 /$ sul 3041903

Freire-Gonzalez, J., and Vivanco, D. F. (2020). Pandemics and the environmental rebound effect: reflections from COVID-19. Environ. Resour. Econ. 76, 462-465. doi: 10.1007/s10640-020-00448-7

Fuchs, D., Sahakian, M., Gumbert, T, Di Guilio, A., Maniates, M., Lorek, S., and Graf, A. (2021). Consumption Corridors. Living a Good Life Within Sustainable Limits. London: Routlege. doi: 10.4324/9780367748746

Gössling, S. (2020). Risks, resilience, and pathways to sustainable aviation: a COVID-19 perspective. J. Air Transp. Manag. 89:101933. doi: 10.1016/j.jairtraman.2020.101933

Gössling, S., and Humpe, A. (2020). The global scale, distribution and growth of aviation: implications for climate change. Glob. Environ. Change-Human Policy Dimen. 65:102194. doi: 10.1016/j.gloenvcha.2020.102194

Hall, C. M., Scott, D., and Gössling, S. (2020). Pandemics, transformations and tourism: be careful what you wish for. Tour. Geogr. 22, 577-598. doi: $10.1080 / 14616688.2020 .1759131$

Hossain, M. (2021). The effect of the Covid-19 on sharing economy activities. J. Clean Prod. 280, 1-9. doi: 10.1016/j.jclepro.2020.124782

IPCC (2021). Climate Change 2021: The Physical Science Basis. Available online at: https://www.ipcc.ch/report/sixth-assessment-report-working-group-i/ (accessed August 19, 2021).

Iqbal, S., Bilal, A. R., Nurunnabi, M., Iqbal, W., Alfakhri, Y., and \& Iqbal, N. (2020). It is time to control the worst: testing COVID-19 outbreak, energy consumption and $\mathrm{CO}_{2}$ emission. Environ. Sci. Pollut. Res. 28, 19008-19020. doi: $10.1007 / \mathrm{s} 11356-020-11462-\mathrm{z}$

Jackson, T. (2017). Prosperity Without Growth. Foundations for the Economy of Tomorrow (2nd ed). London: Routledge.

Jiang, P., Van Fan, Y., and Klemes, J.J. (2021). Impacts of COVID-19 on energy demand and consumption: challenges, lessons and emerging opportunities. Applied Energy 285, 116441-116441. doi: 10.1016/j.apenergy.2021.116441

Jo, H., Shin, E., and Kim, H. (2021). Changes in consumer behaviour in the post-COVID-19 era in Seoul, South Korea. Sustainability 13:136. doi: 10.3390/su13010136

Jones, P., and Comfort, D. (2020). The COVID-19 crisis and sustainability in the hospitality industry. Int. J. Contemp. Hosp. Manag. 32, 3037-3050. doi: 10.1108/IJCHM-04-2020-0357

Kallis, G., Kostakis, V., Lange, S., Muraca, B., Paulson, S., and Schmelzer, M. (2018). Research on Degrowth. Annu. Rev. Environ. Resourc. 43, 291-316. doi: $10.2307 /$ j.ctv5cg82g

Kanda, W., and Kivimaa, P. (2020). What opportunities could the COVID19 outbreak offer for sustainability transitions research on electricity and mobility? Energy Res. Soc. Sci. 68:101666. doi: 10.1016/j.erss.2020.1 01666
Kirk, C. P., and Rifkin, L.S. (2020). I'll trade you diamonds for toilet paper: consumer reacting, coping and adapting behaviors in the COVID-19 pandemic. J. Bus. Res. 117, 124-131. doi: 10.1016/j.jbusres.2020.05.028

Lidskog, R., Elander, I., and Standring, A. (2020). COVID-19, the climate, and transformative change: comparing the social anatomies of crises and their regulatory responses. Sustainability 12:6337. doi: 10.3390/su12166337

Mont, O., Curtis, S. K., and Palgan, Y. V. (2021). Organisational response strategies to COVID-19 in the sharing economy. Sustain. Prod. Consump. 28, 52-70. doi: $10.1016 /$ j.spc.2021.03.025

Perkins, K. M., Munguia, N., Elfenbecker, M., Moure-Eraso, R., and Velazquez, L. (2021). COVID-19 pandemic lessons to facilitate future engagement in the global climate crisis. J. Clean. Prod. 290:125178. doi: $10.1016 /$ j.jclepro.2020.125178

Princen, T. (2005). The Logic of Sufficiency. Cambridge, US: The MIT Press.

Schor, J. B., and Thompson, C. J. (eds) (2014). Sustainable Lifestyles and the Quest for Plenitude: Case Studies of the New Economy. New Haven: Yale University Press.

Severo, E. A., Ferro de Guimaraes, J. C., and Dellarmelin, M. L. (2021). Impact of the COVID-19 pandemic on environmental awareness, sustainable consumption and social responsibility: evidence from generations in Brazil and Portugal. J. Clean. Prod. 286:124947. doi: 10.1016/j.jclepro.2020.124947

Shamshiripour, A., Rahimi, E., Shabounpour, R., and Mohammadian, A. (2020). How is COVID-19 reshaping activity-travel behavior? Evidence from a comprehensive survey in Chicago. Transp. Res. Interdiscip. Perspect. 7:100216. doi: $10.1016 /$ j.trip.2020.100216

Sheth, J. (2020). Impact of Covid-19 on consumer behavior: will the old habits return or die? J. Bus. Res. 117, 280-283. doi: 10.1016/j.jbusres.2020.05.059

Snyder, H. (2019). Literature review as a research methodology: an overview and guidelines. J. Bus. Res. 104, 333-339. doi: 10.1016/j.jbusres.2019.07.039

Spash, C. L. (2020). "The economy" as if people mattered: revisiting critiques of economic growth in a time of crisis. Globalizations 2020, 1-18. doi: $10.1080 / 14747731.2020 .1761612$

Stegeman, I., Godfrey, A., Romeo-Velilla, M., Bell, R., Staatsen, B., van der Vliet, N., et al. (2020). Encouraging and enabling lifestyles and behaviours to simultaneously promote environmental sustainability, health and equity: key policy messages from inherit. Int. J. Environ. Res. Public Health 17, 1-22. doi: 10.3390/ijerph17197166

Tchetchik, A., Kaplan, S., and Blass, V. (2021). Recycling and consumption reduction following the COVID-19 lockdown: the effect of threat and coping appraisal, past behavior and information. Resour. Conserv. Recycl. 167:105370. doi: 10.1016/j.resconrec.2020.105370

Wen, J., Kozak, M., Yang, S., and Liu, F. (2020). COVID-19: potential effects on Chinese citizens' lifestyle and travel. Tour. Rev. 76, 74-87. doi: 10.1108/TR-03-2020-0110

Zhang, J., Hyashi, Y., and Frank, L.D. (2021). COVID-19 and transport: findings from a world-wide expert survey. Transp. Policy 103, 68-85. doi: 10.1016/j.tranpol.2021.01.011

Zwanka, R. J., and Buff, C. (2020). COVID-19 generation: a conceptual framework of the consumer behavioral shifts to be caused by the COVID-19 pandemic. J. Int. Consum. Market. 33, 58-67. doi: 10.1080/08961530.2020.1771646

Conflict of Interest: The author declares that the research was conducted in the absence of any commercial or financial relationships that could be construed as a potential conflict of interest.

Publisher's Note: All claims expressed in this article are solely those of the authors and do not necessarily represent those of their affiliated organizations, or those of the publisher, the editors and the reviewers. Any product that may be evaluated in this article, or claim that may be made by its manufacturer, is not guaranteed or endorsed by the publisher.

Copyright $\odot 2021$ Boström. This is an open-access article distributed under the terms of the Creative Commons Attribution License (CC BY). The use, distribution or reproduction in other forums is permitted, provided the original author $(s)$ and the copyright owner(s) are credited and that the original publication in this journal is cited, in accordance with accepted academic practice. No use, distribution or reproduction is permitted which does not comply with these terms. 